\title{
Noninvasive mechanical ventilation with high pressure strategy remains a "double edged sword"?
}

\author{
Antonio M Esquinas' \\ Gherardo Siscaro ${ }^{2}$ \\ Enrico M Clini ${ }^{2}$ \\ 'Intensive Care Unit, Hospital Morales \\ Meseguer, Murcia, ${ }^{2}$ Department \\ of Medical and Surgical Sciences, \\ University of Modena, Pavullo- \\ Modena, Italy
}

This article was published in the following Dove Press journal:

International Journal of COPD

24 May 2013

Number of times this article has been viewed

\section{Dear editor}

We read with great interest the original work by Murphy et al analyzing the effects of two treatment strategies for delivery of noninvasive mechanical ventilation in hypercapnic patients with chronic obstructive pulmonary disease. ${ }^{1}$ High pressure and high intensity noninvasive mechanical ventilation were compared in a short-term crossover trial to assess whether high intensity noninvasive mechanical ventilation (inspiratory pressure $>25 \mathrm{~cm} \mathrm{H}_{2} \mathrm{O}$ associated with a high backup ventilator rate) may improve adherence, physiological, and subjective outcomes when compared with delivery of high pressure noninvasive mechanical ventilation (without elevated backup respiratory rate). The authors concluded that both strategies are equivalent in all the recorded outcomes, showing thus that driving pressure, but not backup respiratory rate, is essential to gain physiological and clinical benefits in this population when in a chronic stable condition.

Despite previous randomized studies showing the potential benefits of long-term noninvasive mechanical ventilation in hypercapnic patients with chronic obstructive pulmonary disease, current research has still not clearly indicated the best strategy to improve the patient's adherence with treatment. ${ }^{2,3}$ Overall, dropout during noninvasive mechanical ventilation remains a serious clinical problem. ${ }^{4}$ This study provides valuable information in this regard, suggesting that sufficiently high-pressure delivery is enough to achieve useful clinical and physiological goals.

This notwithstanding, we believe that some of the expectations following the adoption of these different noninvasive mechanical ventilation strategies have not been adequately addressed in the present study. Therefore, we consider that it would be useful, from a practical point of view, to underline some points in this regard.

First, the authors did not determine what effects the highest respiratory backup rate used in their study may have had. Although there have been no major studies published on application of high levels of backup that have proved to be useful in patients with severe chronic obstructive pulmonary disease, this is the best indication for hypoventilation syndromes, ie, obesity and overlap syndromes. In fact, we cannot exclude that addition of a high backup respiratory rate may help to resolve "overlap" when present at a subclinical level in patients with chronic obstructive pulmonary disease, or that it has not been adequately assessed before. However, it seems that the authors selected backup respiratory rate levels on a clinical basis without any physiological assessment in their study population. Despite patients in the present
Correspondence: Antonio M Esquinas Intensive Care Unit, Hospital Morales Meseguer, Avenida Marques Velez s/n, Murcia, 30008, Spain

Email antmesquinas@gmail.com 
study not appearing to show any abnormal increase in their body mass index, the extrapolated conclusion of a lack of additional benefit from a well assessed strategy, including adequate backup respiratory rate, cannot be firmly excluded in such "extreme" cases. ${ }^{5}$

Second, there was a lack of complementary tests in this study that might have helped in analysis of the data. Indeed, the authors selected patients with a $\mathrm{FEV}_{1}$ (forced expiratory volume in one second) that could worsen with high backup and pressure, especially with the auto-positive endexpiratory pressure mechanism. It is not clear how selection of expiratory-positive airway pressure was made in the study population. Similarly, the authors did not take into account any potential auto-positive end-expiratory pressure effects during the 6-week period of observation.

Third, the authors arbitrarily selected a population of hypercapnic patients with chronic obstructive pulmonary disease (daytime $\mathrm{PaCO}_{2}>6 \mathrm{kPa}$ ) which would not be universally recognized as the most appropriate in terms of risk of frequency of exacerbations and clinical instability, and it is not clear whether any other additional clinical factors behind cardiac dysfunction may have interfered at admission or over the study period. ${ }^{6}$ Indeed, three of the five patients who withdrew did so because of factors other than mere mask/pressure intolerance (see Table E1). ${ }^{1}$

Final, there was no analysis of potential implications of air leakage in the observed results. No mention was made of measurement or monitoring of leakage during application of noninvasive mechanical ventilation. This aspect could have been potentially relevant and interfered with the results, especially during application of such high-pressure delivery, which is known to increase mask leakages. ${ }^{4}$
To conclude, we recognize that the paper by Murphy et $\mathrm{al}^{1}$ will add information to the complex process of setting and titration of noninvasive mechanical ventilation in the population of stable hypercapnic patients with chronic obstructive pulmonary disease. However, given the observations discussed, we are convinced that further studies of longer duration and including larger numbers of patients are needed to determine which physiological effects should be assessed and expected during application of both strategies. Currently, high-pressure strategies remain a "double edged sword" in daily practice.

\section{Disclosure}

The authors report no conflicts of interest in this communication.

\section{References}

1. Murphy PB, Brignall K, Moxham J, Polkey MI, Davidson AC, Hart N. High pressure versus high intensity noninvasive ventilation in stable hypercapnic chronic obstructive pulmonary disease: a randomized crossover trial. Int J Chron Obstruct Pulmon Dis. 2012;7:811-818.

2. Clini E, Sturani C, Rossi A, et al; Rehabilitation and Chronic Care Study Group, Italian Association of Hospital Pulmonologists (AIPO). The Italian multicentre study on noninvasive ventilation in chronic obstructive pulmonary disease patients. Eur Respir J. 2002;20:529-538.

3. McEvoy RD, Pierce RJ, Hillman D, et al; Australian trial of non-invasive Ventilation in Chronic Airflow Limitation (AVCAL) Study Group. Nocturnal non-invasive nasal ventilation in stable hypercapnic COPD: a randomised controlled trial. Thorax. 2009;64:561-566.

4. Dreher M, Ekkernkamp E, Walterspacher S, et al. Noninvasive ventilation in COPD: impact of inspiratory pressure levels on sleep quality. Chest. 2011;140:939-945.

5. Porta R, Vitacca M, Clini E, Ambrosino N. Physiological effects of posture on mask ventilation in awake stable chronic hypercapnic COPD patients. Eur Respir J. 1999;14:517-522.

6. De Backer L, Vos W, Dieriks B, et al. The effects of long-term noninvasive ventilation in hypercapnic COPD patients: a randomized controlled pilot study. Int J Chron Obstruct Pulmon Dis. 2011;6:615-624. 


\section{Authors' reply}

Patrick B Murphy'

Kate Brignall'

John Moxham ${ }^{2}$

Michael I Polkey ${ }^{3}$

A Craig Davidson'

Nicholas Hart ${ }^{1,4}$

'Lane Fox Clinical Respiratory Physiology Group, Guy's and St Thomas' NHS Foundation Trust, ${ }^{2}$ Department of Thoracic Medicine, King's College Hospital, ${ }^{3}$ Sleep and Ventilation Unit, Royal Brompton and Harefield NHS Foundation Trust, ${ }^{4}$ Guy's and St Thomas' NHS Foundation Trust and Kings College London NIHR Comprehensive Biomedical Research Centre,

London, UK

Correspondence: Patrick Murphy

Lane Fox Respiratory Unit, St Thomas' Hospital,

Westminster Bridge Road, London, SEI 7EH, UK

Tel +44207188 8070

Fax +442071886116

Email patrick.b.murphy@kcl.ac.uk

\section{Dear editor}

We thank Esquinas et al for their thoughtful comments on our recent published trial. We acknowledge that the set backup rate in the high-intensity group was determined clinically. However, the low triggering rate recorded in the high-intensity arm indicates that these patients were largely in mandatory ventilation, ie, by definition, they received high-intensity ventilation. Further, we consider that the high backup rate would be expected to contribute further to intrinsic positive end-expiratory pressure because the lung emptying at the end of expiration would be incomplete as the ventilator cycles from expiration to inspiration early, which would contribute greater patient-ventilator asynchrony. Patients with obstructive sleep apnea and/or obesity hypoventilation syndrome were excluded from the study because this is the group most likely to benefit from addition of a backup rate, a point highlighted by Esquinas et al. In a post hoc analysis of another recently published trial, a backup rate of 14 breaths per minute in obese patients was more important in controlling nocturnal hypoventilation than the mode of ventilation per se.

The expiratory-positive airway pressure setting in the study was selected according to the ventilation setup algorithm provided in Figure E1. ${ }^{2}$ The major clinical drive to undertake this trial was a physiological concern that use of high-intensity noninvasive mechanical ventilation in chronic obstructive pulmonary disease would exacerbate intrinsic positive end-expiratory pressure and subsequently have an adverse effect on outcome. Although the high-intensity mode has been shown to provide superior control of nocturnal hypoventilation compared with the low-intensity mode, ${ }^{3}$ it has not been compared with a high-pressure strategy alone until the current published trial. The authors considered that this would have a lesser impact on patient-ventilator asynchrony, although we acknowledge that we did not make detailed physiological measurements in this randomized, controlled clinical trial. However, the expected adverse clinical impact of intrinsic positive end-expiratory pressure would be a worsening of patient-ventilator synchrony, and this would be reflected in a reduction in patient subjective or objective assessment of sleep, recorded in the study by visual analog score and actigraphy, respectively. Neither marker indicated a treatment effect in the current study. The earlier work by Dreher et al, which compared a high-intensity versus lowintensity approach, again failed to show a difference in subjective or objective sleep during application of noninvasive mechanical ventilation. ${ }^{4}$

Earlier work using low-pressure strategies has failed to demonstrate unequivocally a clinical benefit of noninvasive mechanical ventilation in hypercapnic chronic obstructive pulmonary disease and, as such, there is debate as to the phenotype of patient that will benefit most from domiciliary noninvasive mechanical ventilation. Thus, the current inclusion criteria are to some extent arbitrary, and the selection of patients was clearly described in the methods. Currently, there is a great deal of interest in which patients benefit most from domiciliary noninvasive mechanical ventilation, and this is the focus of ongoing European trials (HoT-HMV UK, NCT00990132, NCT00710541). On a related point, we agree with Esquinas et al that patients with chronic obstructive pulmonary disease and a significantly elevated $\mathrm{PaCO}_{2}$ are most likely to benefit, as was shown in the current trial, given that the mean $\mathrm{PaCO}_{2}$ was $8.5 \pm 1.8 \mathrm{kPa}$.

Finally, measurements of air leak were not performed in the current trial, and addition of these data could have enhanced the paper and provided useful information for the clinician when applying the study conclusions in clinical practice. The authors acknowledge that ventilator settings and higher pressure may well be associated with higher levels of leak and that these may interfere with patient-ventilator synchrony and thus adherence with noninvasive mechanical ventilation. ${ }^{5}$

The data from the current study add to the previously published data to allow the clinician greater scope in the management of these complex and challenging patients. 
In essence, control of nocturnal hypoventilation should be the therapeutic goal of noninvasive mechanical ventilation in chronic obstructive pulmonary disease. The ventilation strategy requires a personalized approach that is modeled for the individual patient and, as such, the clinician must always remember that there is "more than one way to skin a cat".

\section{Acknowledgment}

This letter is published on behalf of the UK HoT-HMV Trial (UK CRN Trial 8059)

\section{Disclosure}

The authors report no conflicts of interest in this communication.

\section{References}

1. Murphy PB, Davidson C, Hind MD, et al. Volume targeted versus pressure support non-invasive ventilation in patients with super obesity and chronic respiratory failure: a randomised controlled trial. Thorax. 2012;67:727-734.

2. Murphy PB, Brignall K, Moxham J, Polkey MI, Davidson AC, Hart N. High pressure versus high intensity noninvasive ventilation in stable hypercapnic chronic obstructive pulmonary disease: a randomized crossover trial. Int J Chron Obstruct Pulmon Dis. 2012;7:811-818.

3. Dreher M, Storre JH, Schmoor C, Windisch W. High-intensity versus low-intensity non-invasive ventilation in patients with stable hypercapnic COPD: a randomised crossover trial. Thorax. 2010;65:303-308.

4. Dreher M, Ekkernkamp E, Walterspacher S, et al. Noninvasive ventilation in COPD: impact of inspiratory pressure levels on sleep quality. Chest. 2011;140:939-945.

5. Adler D, Perrig S, Takahashi H, et al. Polysomnography in stable COPD under non-invasive ventilation to reduce patient-ventilator asynchrony and morning breathlessness. Sleep Breath. 2012;16:1081-1090.

\section{Publish your work in this journal}

The International Journal of COPD is an international, peer-reviewed journal of therapeutics and pharmacology focusing on concise rapid reporting of clinical studies and reviews in COPD. Special focus is given to the pathophysiological processes underlying the disease, intervention programs, patient focused education, and self management protocols.

\section{Dovepress}

This journal is indexed on PubMed Central, MedLine and CAS. The manuscript management system is completely online and includes a very quick and fair peer-review system, which is all easy to use. Visit $\mathrm{http} / / / \mathrm{www}$.dovepress.com/testimonials.php to read real quotes from published authors. 